\title{
Title:
}

\section{Open wound and cutaneous fistulization after microwave ablation of hepatocarcinoma}

\section{Authors:}

Pablo Ladrón Abia, Daniel Mateos Millán, Adrián Picazo Bermúdez, Victoria Aguilera Sancho-Tello

DOI: $10.17235 /$ reed.2022.8663/2022

Link: PubMed (Epub ahead of print)

Please cite this article as:

Ladrón Abia Pablo, Mateos Millán Daniel, Picazo Bermúdez Adrián, Aguilera Sancho-Tello Victoria. Open wound and cutaneous fistulization after microwave ablation of hepatocarcinoma. Rev Esp Enferm Dig 2022. doi:

$10.17235 /$ reed.2022.8663/2022.

This is a PDF file of an unedited manuscript that has been accepted for publication. As a service to our customers we are providing this early version of the manuscript. The manuscript will undergo copyediting, typesetting, and review of the resulting proof before it is published in its final form. Please note that during the production process errors may be discovered which could affect the content, and all legal disclaimers that apply to the journal pertain. 


\section{Open wound and cutaneous fistulization after microwave ablation of hepatocarcinoma}

Pablo Ladrón Abia ${ }^{1}$, Daniel Mateos Millán ${ }^{2}$, Adrián Picazo Bermúdez ${ }^{3}$, Victoria Aguilera ${ }^{1}$.

Corresponding author: Pablo Ladrón Abia. Correo: pablo.ladronabia@gmail.com

1. Hepatology Department. Hospital Universitario y Politécnico La Fe. Valencia, Spain.

2. Hepatology Department. Hospital Universitario de Jerez. Jerez de la Frontera, Spain.

3. Interventional Radiology Department. Hospital Universitario y Politécnico La Fe. Valencia, Spain.

\section{CASE REPORT:}

A 64-year-old male with a history of HBV Child A MELD 9 cirrhosis on treatment with oral entecavir $0.5 \mathrm{mg} /$ day. Diagnosed with $2 \mathrm{~cm}$ hepatocarcinoma in segment 6 treated by radiofrequency in April 2016 with complete response until June 2021, when an increase in the size of the solid component of the treated lesion $(28 \times 20 \mathrm{~mm}$ in diameter) was detected with early enhancement after the administration of paramagnetic contrast, suggestive of local tumor recurrence. After presenting to the multidisciplinary committee, microwave ablation of the tumor lesion was performed in October 2021, for which three $17 \mathrm{G}$ microwave antennas were placed. Its correct placement was verified by XperCT and the lesion was ablated for 10 minutes at $90 \mathrm{~W}$ (30 W each antenna) with subsequent ablation of the tract. After the procedure, there was no uptake of the tumor lesion with perilesional hyperemia, and a control CT scan was scheduled a month later. Ten days after the procedure, he was hospitalized due to the appearance of an open suppurative wound in the right subcostal region (access area for percutaneous ablation), with no associated fever (Figure 1A). An abdominopelvic CT scan was performed with the findings described in Figure 2B. Given the clinical and radiological findings, the patient was hospitalized. In the bacteriological 
culture of the purulent exudate, Escherichia coli was isolated (treated by oral antibiotic therapy with ciprofloxacin $500 \mathrm{mg} / 12$ hours for 7 days) and local cures were performed with physiological saline solution and chlorhexidine with decreased wound drainage. Nine days after discharge, negative pressure therapy was placed using VAC (Vacuum Assisted Closure) system at $80 \mathrm{mmHg}$ pressure for 7 weeks with good progress after removal (Figure $1 \mathrm{C}$ ).

Microwave ablation is a percutaneous thermal treatment that creates an electromagnetic field around a monopolar electrode, inducing homogeneous heating and coagulative tissue necrosis. It allows treating several lesions simultaneously and in less time than radiofrequency ablation with low morbidity and mortality. The incidence of adverse events ranges between $2.6 \%$ and $7.5 \%$. The most frequent complications are bleeding and hematoma. Ablation tract fistulization is an infrequent complication, with a higher risk of appearing in subcapsular or peripheral hepatic lesions, as was the case in our patient.

Conflicts of interest: There are no conflicts of interest.

Funding: None.

\section{REFERENCES:}

1. Liang $P$, Wang $Y, Y u X$, et al. Malignant liver tumors: treatment with percutaneous microwave ablation--complications among cohort of 1136 patients. Radiology. 2009; 251:933-940.

2. Dong $B$, Liang $P, Y u X$, et al. Percutaneous sonographically guided microwave coagulation therapy for hepatocellular carcinoma: results in 234 patients. AJR Am J Roentgenol. 2003; 180:1547-1555.

3. Ma S, Ding M, Li J, et al. Ultrasound-guided percutaneous microwave ablation for hepatocellular carcinoma: clinical outcomes and prognostic factors. J Cancer Res Clin Oncol. 2017; 143:131-142. 
4. Rogger TM, Michielan A, Sferrazza S, et al. Gastrointestinal tract injuries after thermal ablative therapies for hepatocellular carcinoma: A case report and review of the literature. World J Gastroenterol. 2020; 26:5375-5386.
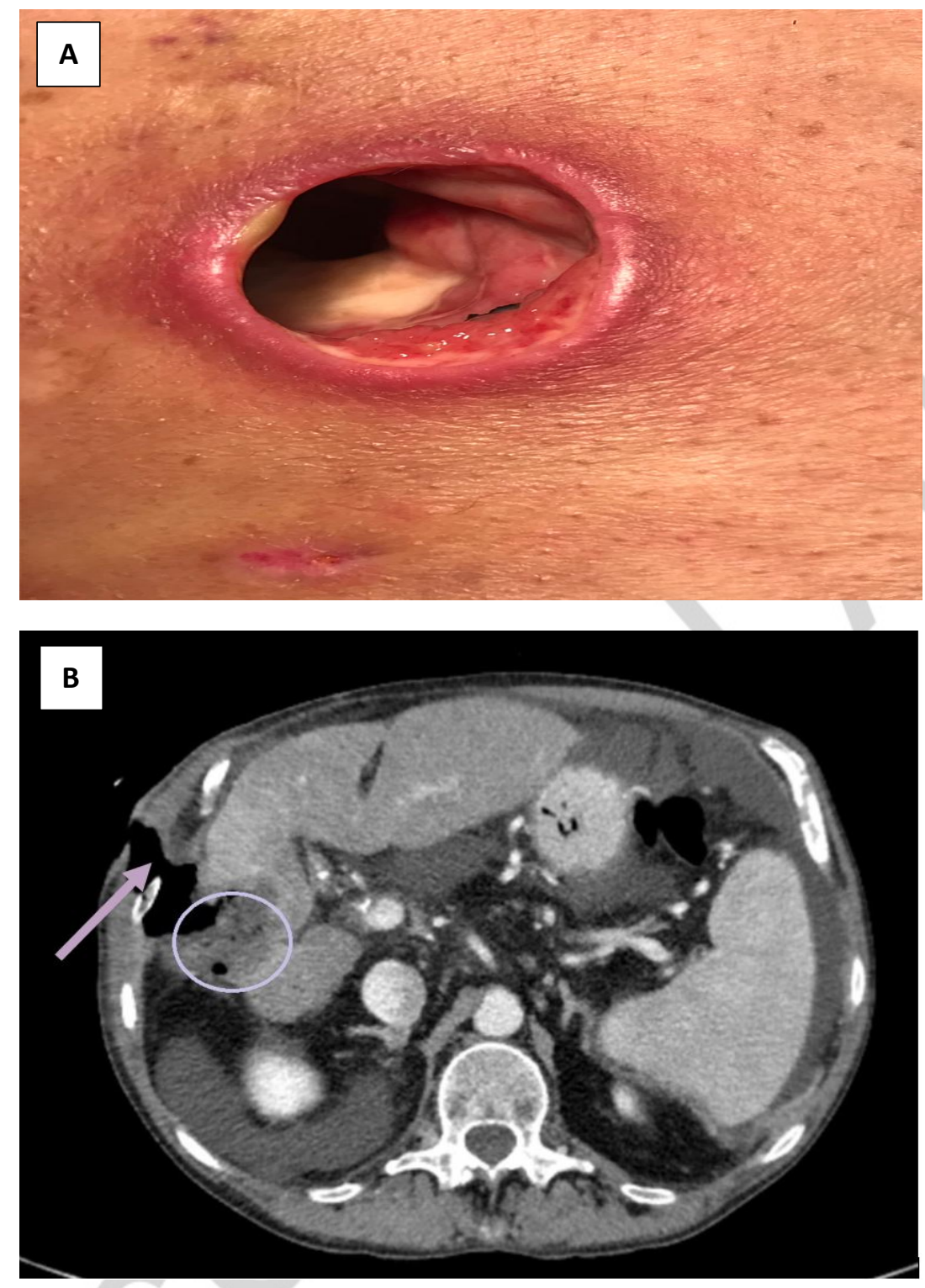

\section{C}




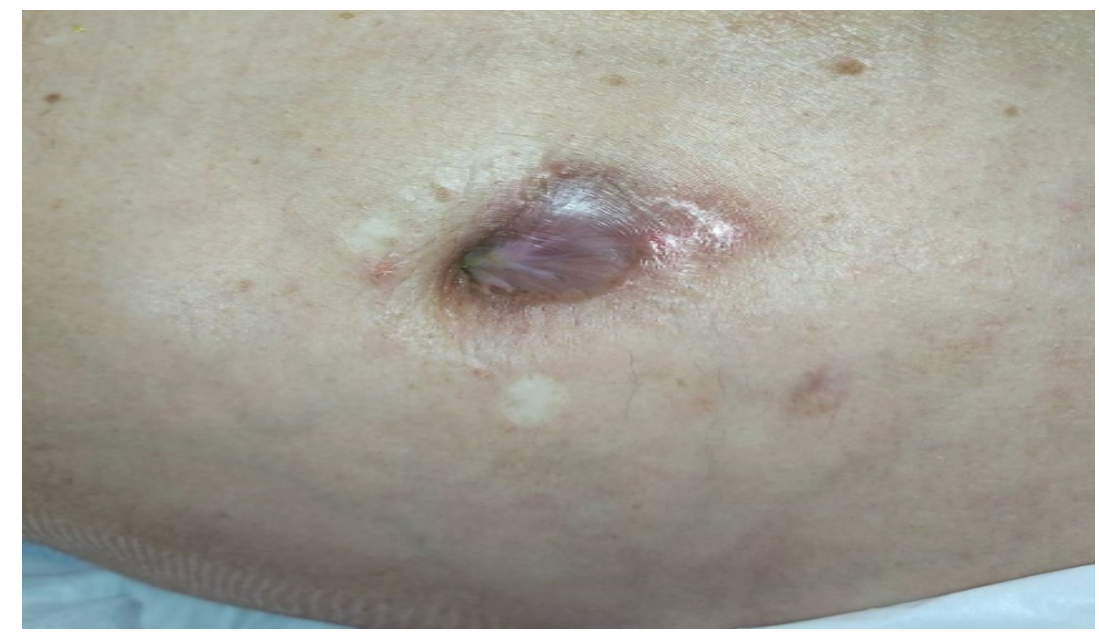

Figure 1. A. $2 \mathrm{~cm}$ diameter wound with continuity solution in the right subcostal region. Purulent and exudative appearance with a depth of $5 \mathrm{~cm}$ towards the liver. $\mathbf{B}$. Anfractuous air-fluid collection measuring $70 \times 44 \times 33 \mathrm{~mm}$ in the area of tumor ablation (circle) with a fistulous tract to the skin surface (arrow). A continuity solution is observed in intercostal space between the $8^{\text {th }}$ and $9^{\text {th }}$ rib of approximately $2 \mathrm{~cm}$. Known partial chronic extrahepatic portal thrombosis. C. $2 \mathrm{~cm}$ deep wound without suppuration and retracted edges in the right subcostal region. 